\title{
Intoxicaciones por alcohol y accidentes mortales en Bielorrusia
}

\section{Alcohol poisonings and fatal accidents in Belarus}

\author{
Y. E. RAZVODOVSKY
}

\author{
Grodno State Medical University, Belarus. \\ Enviar correspondencia a: \\ Yury E. Razvodovsky \\ Grodno State Medical University, Belarus. \\ str. Gorky 80, 230009, Grodno, Belarus. \\ E-mail: yury_razvodovsky@mail.ru; razvodovsky@tut.by
}

\section{RESUMEN}

Antecedentes: Alta tasa de muertes accidentales en las antiguas repúblicas soviéticas (ARS) y sus grandes fluctuaciones en las últimas décadas han atraído un interés considerable. Aumenta la evidencia que apunta hacia un patrón de consumo intensivo de alcohol como un factor potencialmente importante en la crisis de mortalidad por accidentes en las ARS.

Objetivo: El objetivo de este estudio fue estimar el efecto a nivel agregado del consumo intensivo de alcohol en la tasa de mortalidad por accidentes en la ex república soviética de Bielorrusia.

Método: Las tendencias en la intoxicación alcohólica grave (como un proxy para consumo excesivo de alcohol) y las tasas de muertes por accidente desde 1979 hasta 2007 son analizadas mediante un análisis de series temporales distribuidas con el fin de evaluar la relación bivariante entre las dos series temporales.

Resultados: De acuerdo con los informes sobre autopsias de la Oficina de Medicina Forense el número de muertes debido a accidentes y lesiones aumentaron un 94,5\% (38,7 a 75,6 por 100.000 habitantes), y la tasa de intoxicación etílica fatal aumentó en un 108,6\% (12,8 a 26,7 por 100.000 de los residentes) en Bielorrusia entre 1979 y 2007. El alcohol en la sangre se encontró en el 51.4\% de las víctimas de muertes por accidentes y lesiones durante todo el período, con la cifra mínima de 43,1\% en 1986 y 59,1\% como máximo en 2005. El resultado del análisis de series temporales distribuídas indicó una asociación estadísticamente significativa entre el número de muertes por envenenamiento por alcohol y el número de alcoholemias positivas en muertes por accidentes y lesiones en el intervalo cero.

Conclusión: El resultado de este estudio apoya la hipótesis de que el alcohol y las muertes por accidentes y lesiones están estrechamente relacionada con una cultura con un patrón de consumo orientado a la intoxicación. Esta investigación apunta hacia que el patrón de consumo intensivo de alcohol en Bielorrusia es un factor potencialmente importante en la crisis de mortalidad por accidentes de dicho pais.

Palabras claves: accidentes, intoxicación alcohólica, series temporales, Bielorrusia. recibido: febrero 2011 aceptado: marzo 2011

\section{ABSTRACT}

Background: High accidental deaths rate in the former Soviet republics (FSR) and its profound fluctuation over the past decades have attracted considerable interest. The mounting body of evidence point to binge drinking pattern as a potentially important contributor to accident mortality crisis in FSR.

Aim: The aim of this study was to estimate the aggregate-level effect of binge drinking on the accident mortality rate in the former Soviet Slavic republic Belarus.

Method: Trends in fatal alcohol poisoning (as a proxy for binge drinking) and accidental deaths rates from 1979 to 2007 were analyzed employing a distributed lag analysis in order to asses bivariate relationship between the two time series.

Results: According to Bureau of Forensic Medicine autopsy reports the number of deaths due to accidents and injuries increased by 94.5\% (from 38.7 to 75.6 per 100.000 of residents), and fatal alcohol poisoning rate increased by $108.6 \%$ (from 12.8 to 26.7 per 100.000 of residents) in Belarus between 1979 and 2007. Alcohol in blood was found in $51.4 \%$ victims of deaths from accidents and injuries for the whole period, with the minimum figure $43.1 \%$ in 1986 and maximum $59.1 \%$ in 2005. The outcome of distributed lags analysis indicated statistically significant association between the number of alcohol poisoning deaths and the number BAC (blood alcohol concentration)positive deaths from accidents and injuries at zero lag.

Conclusion: The outcome of this study supports the hypothesis that alcohol and deaths from accidents and injuries are closely connected in culture with prevailing intoxication-oriented drinking pattern. This research evidence points to binge drinking pattern as a potentially important contributor to accident mortality crisis in Belarus.

Key words: accidents, alcohol intoxication, distributed lag analysis, Belarus. 


\section{INTRODUCTION}

A Ithough alcohol is a major risk factor of accidental death in many regions of the world, Europe has the highest alcohol-attributable burden of accident mortality (Edwards, Anderson, Babor, Casswell, Ferrence, Giesbrecht, Godfrey, Holder \& Lemmens, 1994; Anderson \& Baumberg, 2006). According to recent estimates unintentional injury was the category which accounted for most deaths $(49,9 \%)$ and years of life lost (YLL) $(60,3 \%)$ in Europe (Rehm, Sulkowska, Manczuk, Boffeta, Powles, Popova \& Zatonski, 2007).

It is widely recognized that acute alcohol intoxication is associated with an increased risk for different types of accidents (Cherpitel, 1993; Anda, Williamson \& Remington, 1995; Treno, Gruenewald \& Ponicki, 1997). Excessive alcohol consumption is a major cause of considerable number of fatal traffic accidents throughout the world (Zador, 1991; Cunningham, Maio, Hill \& Zink, 2002; Mayhew, Donelson, Beirness \& Simpson, 1986). In many countries alcohol also plays a significant role in accidental falls, accidents caused by fire, accidental drowning (Higson \& Howland, 1987; Edwards et al., 1994)

There is evidence of a strong association between alcohol and accidental deaths at the individual level. In a Czech study, using materials of forensic autopsies, alcohol in the blood has been detected in 34.7\% victims of fatal traffic accidents (Mravik, Vorel \& Zabransky, 2007). Alcohol has been found to be related to 44,49 , and $37 \%$ of accidental deaths among Finish males in the age groups 15-34, 35-54 and 55-59 years (Makela, 1998). A review of studies based on Norwegian data suggests that about $35 \%$ of male fatal accidents were alcohol-related (Skog, 1986). In the US, alcohol may have caused $29 \%$ of all unintentional fatal injuries and more than 40\% fatal motor vehicle crashes (Cunningham, et al. 2002). It was estimated that $45 \%$ of all accidental deaths among males 15-69 years were alcohol-related in northern Europe; the alcohol attributable fraction for southern and central Europe was 40\% and 35\% respectively (Skog, 2001a).

A substantial literature exists on the association between alcohol and non-fatal injury. A cross-sectional study conducted in eight university hospitals in Spain showed that among young patients (<40 years) admitted to emergency departments, $24.7 \%$ of men and $14.8 \%$ of women were positive for alcohol (Pérez, Santamariña-Rubio, RodríguezMartos, Brugal, Ricart, Suelves, de la Torre, Pujadas, Ariza, Díez, Nebot, Ramos, Martinez Beneyto \& Plasència, 2009). The outcomes of another study conducted at Oulu University Hospital (Finland) suggest that 77\% patients injured by falls on the ground (Rivara, Jurkovich, Gurney, Seguin, Fligner, Ries, Raisys \& Copass, 1993). The study of alcohol and injury in the emergency service of a public hospital in Warsaw found that among injured 35\% males and 12\% females reported seven or more drinks during the 6 hour prior to injury (Cherpitel, Moskalewicz \& Swiatkiewicz, 2004). In a prospective cohort study conducted in the US was shown that $47 \%$ of trauma patients had a positive BAC and 35.8\% were intoxicated (BAC more than $100 \mathrm{mg} / \mathrm{dL}$ ) (Savola, Niemela \& Hillbom, 2005]. Overall, a review of international emergency rooms studies found positive BAC estimates among injured patients to range from $6 \%$ to $32 \%$, while self-reported consumption within 6 hour prior to the event ranged from 8\% to 39\% (Cherpitel, 1993).

The strong support for a causal role of alcohol in accidental mortality comes from aggregate-level studies. Both longitudinal and cross-sectional aggregate-level studies have reported elsewhere a significant temporal covariation between per capita alcohol consumption and accidental mortality rates (Norstrom \& Ramstedt, 2005). An analysis of time-series data for Canada covering the period 1950-1998 revealed a statistically significant association between per capita alcohol consumption and overall fatal accidents rates (Skog, 2003). In a cross-sectional time-series analysis based on data from 50 American states, population drinking remained a predictor of traffic fatalities even after controlling for potential confounders (Noland, 2003). Nevertheless, the cross-country comparisons demonstrate heterogeneity with respect to strength of association between population drinking and accidental mortality (Norstrom \& Ramstedt, 2005). In countries where high level of intoxication is an integral part of the drinking culture, the etiological significance of alcohol seems to be larger. A time series analysis, based on the data for the period from 1950-95 covering 14 European Union countries suggests that an increase in population drinking had the largest impact on accident mortality in northern Europe than in mid-Europe and southern Europe (Skog, 2001b). These findings provided support for the hypothesis, that the effect of alcohol on accident mortality rate is stronger in the northern European spirits countries characterized by a low per capita consumption with the bulk of consumption concentrated on a few occasions (binge drinking pattern), or "dry" drinking cultures, than in the southern European wine countries with a high average consumption which is more evenly distributed throughout the week, or "wet" drinking cultures. Similarly, the results of recent study suggest that changes in per capita consumption have a significant impact on injury mortality in 6 eastern European countries, but the strength of the association tends to be stronger in countries where intoxication-oriented drinking pattern prevails (Landberg, 2010).

There is common believe that high level of alcohol consumption in conjunction with binge drinking pattern is a major determinant of accident mortality crisis in the former Soviet republics (FSR)(Moskalewicz, Razvodovsky \& Wieczorek, 2009). It should be noted that according to a worldwide assessment FSR had the most hazardous drinking pattern (Rehm, et al., 2007). The findings suggest that population drinking and accidental deaths rates are positively related phenomena in Russia (Razvodovsky, 2010). It has been estimated that alcohol may be responsible for $49,1 \%$ of all accidental deaths in this country (Nemtsov \& Razvodovsky, 2008).

It should be noted that the in FSR alcohol poisoning rate as an indicator of binge drinking may better capture the magnitude of an intoxication-oriented drinking pattern than official sales statistics and an expert estimation of the total level of alcohol consumption (Stickley, Leinsalu, Andreew, Razvodovsky, Vagero \& McKee 2007). Thus, a common 
approach is to use the fatal alcohol poisoning rate as an indicator of binge drinking in these countries (Pridemore 2006).

The level of alcohol consumption and the accidental mortality rate in the former Soviet Slavic republic Belarus are both among the highest in the world (Razvodovsky 2008). As a predominantly spirits drinking country, Belarus is characterized by infrequent, but heavy (binge) drinking leading to high rates of acute alcohol-related problems (Razvodovsky, 2008).

Although alcohol seems to be an important contributor to the burden of violent mortality in Belarus, little systematic research has been undertaken on its impact on mortality from accidents and injuries in this country. The aim of the present study was to estimate the aggregate-level effect of binge drinking on the accident mortality rate in Belarus by using Bureau of Forensic Medicine autopsy data on the deaths from accidents/injuries and alcohol poisoning between 1979 and 2007.

\section{MATERIAL AND METHODS}

The data on of deaths due to accidents and injures (fatal occupational injuries (ICD codes S00-S99; T 00-T98), accidental falls (W00.0-W19.9), accidents caused by fire (X00-X09), accidental drowning (W65.0-W74.0)) and fatal alcohol poisoning (X45.0-X45.9) used in the article were based on autopsy reports from Bureau of Forensic Medicine. In all 340022 fatal accidents and 59489 fatal alcohol poisoning cases were examined with respect to the autopsy reports between 1979 and 2007. In Belarus, virtually all (99.1\%) violent deaths are subjected to forensic autopsies, which include blood alcohol concentration (BAC) inspection. BAC in samples collected by forensic pathologists during the medical autopsies was assessed by gas chromatography and reported per million $(\%)$. BAC over $0.5 \%$ was termed 'inebriation' and denoted as 'BAC-positive'.

The statistical analysis was performed using the package "Statistica". It is generally agreed that bivariate correlations between two raw time-series are spurious due to common sources of trends and autocorrelation (Norstrom \& Skog, 2001). Therefore in order to reduce the risk of obtaining a spurious relation between two variables that have common trends, the trends should be removed by means of a differencing procedure: $\nabla x_{t}=x_{t}-x_{t-1}$ This means analyzing annual changes rather than raw data (Box \& Jenkins, 1976). The process of removing systematic variation within time series prior to the examination of potential causal relationships is referred to as "prewhitening". The residuals of a statistically adequate time series are distributed as a white noise process. A further step entails the inspection of the cross-correlation function in order to estimate the association between the two prewhitened time series. We used the distributed lags analysis to estimate the relationship between the time series of alcohol poisoning (as a proxy for binge drinking) and deaths due to accidents and injures in this paper.

\section{RESULTS}

According to Bureau of Forensic Medicine autopsy reports the number of deaths due to accidents and injuries increased by $95.4 \%$ (from 38.7 to 75.6 per 100.000 of residents), and fatal alcohol poisonings rate increased by $108.6 \%$ (from 12.8 to 26.7 per 100.000 of residents) in Belarus between 1979 and 2007. The number of BAC-positive deaths due to accidents and injuries increased by $115.4 \%$ (from 18.8 to 40.5 per 100.000 of residents) and number of BAC-negative deaths increased by 76.4\% (from 19.9 to 35.1 per 100.000 of residents). Alcohol in blood was found in $51.4 \%$ victims of deaths from accidents and injuries for the whole period, with the minimum figure $43.1 \%$ in 1986 and maximum 59.1\% in 2005.

A comparative analysis show (Figure 1) that alcoholrelated mortality from accidents and injuries were more affected by the restriction of alcohol availability during the anti-alcohol campaign: between 1984 and 1987 the number of BAC-positive deaths due to accidents and injuries drop by $37.1 \%$ (from 22.1 to 13.9 per 100.000 of residents), while number of BAC-negative deaths decreased by $12.3 \%$ (from 20.3 to 17.8 per 100.000 of residents).

The trends of BAC-positive deaths due to accidents and injuries and alcohol poisonings mortality rates are displayed in Figure 2. As can be seen, there is quite a strong association between the two time series. The two time trends fluctuated over the period: dropped sharply in 1984-1987, began to increase in 1988, dramatically jumped from 1991 to 1998. In 1999/2000 there was a slight decrease in the rates and from 2000 it again began to rise until 2004, than started to decrease in the last years.

As can be seen from Figures 1 there is a linear trend in the time series. This trend was removed by means of firstorder differencing procedure. After pre-whitening the cross-correlations between alcohol poisonings and accident mortality time series were inspected. The outcome indicated statistically significant cross-correlation between fatal alcohol poisoning rate and the number BAC-positive deaths from accidents and injuries ( $r=0.47$; SE 0.189) at zero lag (table 1). At the same time, there is no relation between the fatal alcohol poisoning and BAC-negative accidental deaths. The outcome of the distributed lags analysis is presented in table 2. It can be seen, that the estimated effect of fatal alcohol poisoning rate (as a proxy for binge drinking) on the number BAC-positive deaths due to accidents and injuries is statistically significant at zero lag.

\section{DISCUSSION}

As has been already highlighted, alcohol consumption is proximal risk factor for accident mortality at the individual level. It seems that Belarus is not an exception in this respect. Indeed, more than $50 \%$ of accidental death victims were BAC-positive at time of death. It should be noted, that the proportion of BAC-positive accidental deaths in Belarus is among the highest in the world. 


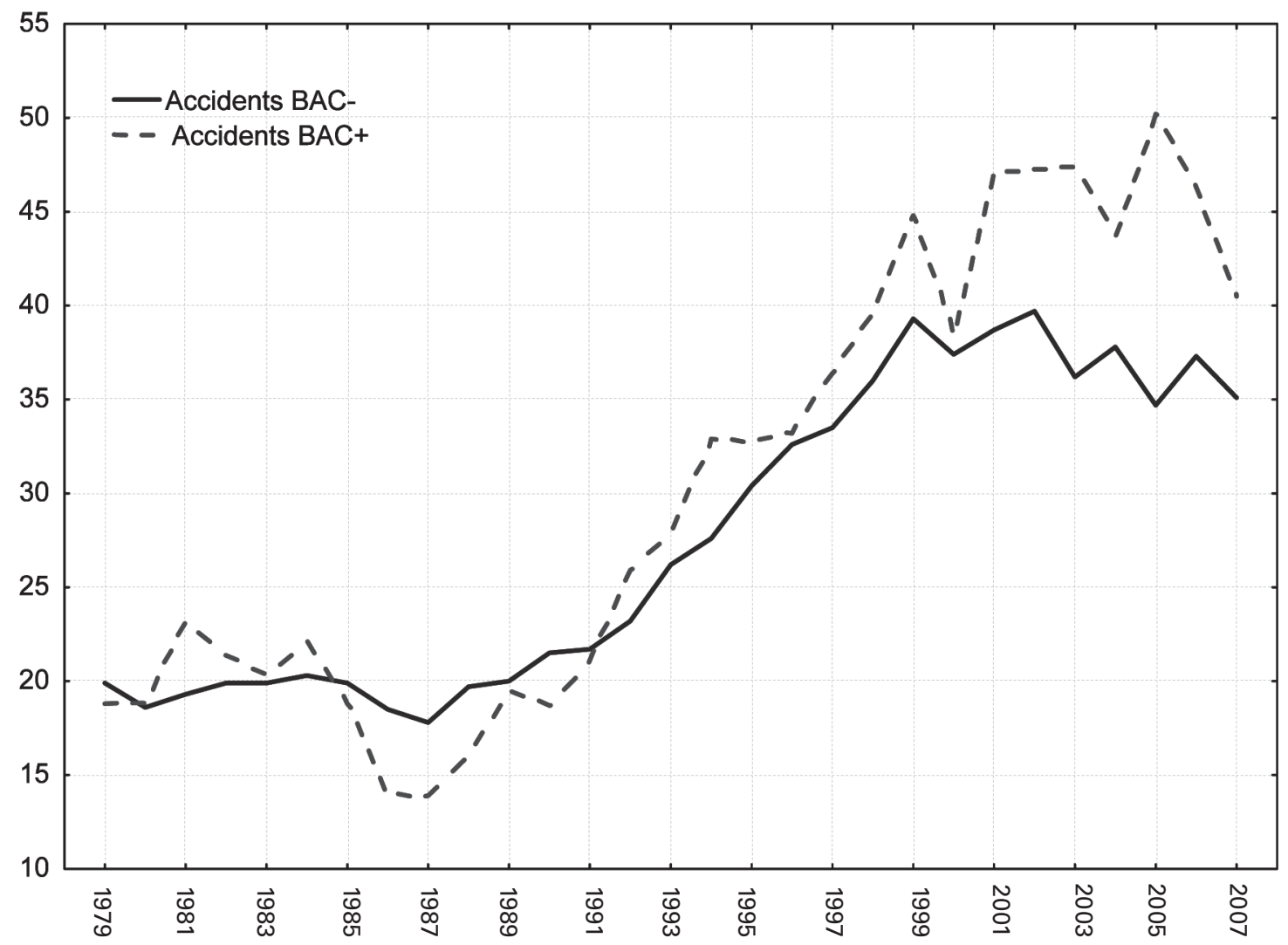

Figure 1. Trends in the number of BAC-positive and BAC-negative cases of deaths from accidents and injuries in Belarus between 1979 and 2007.

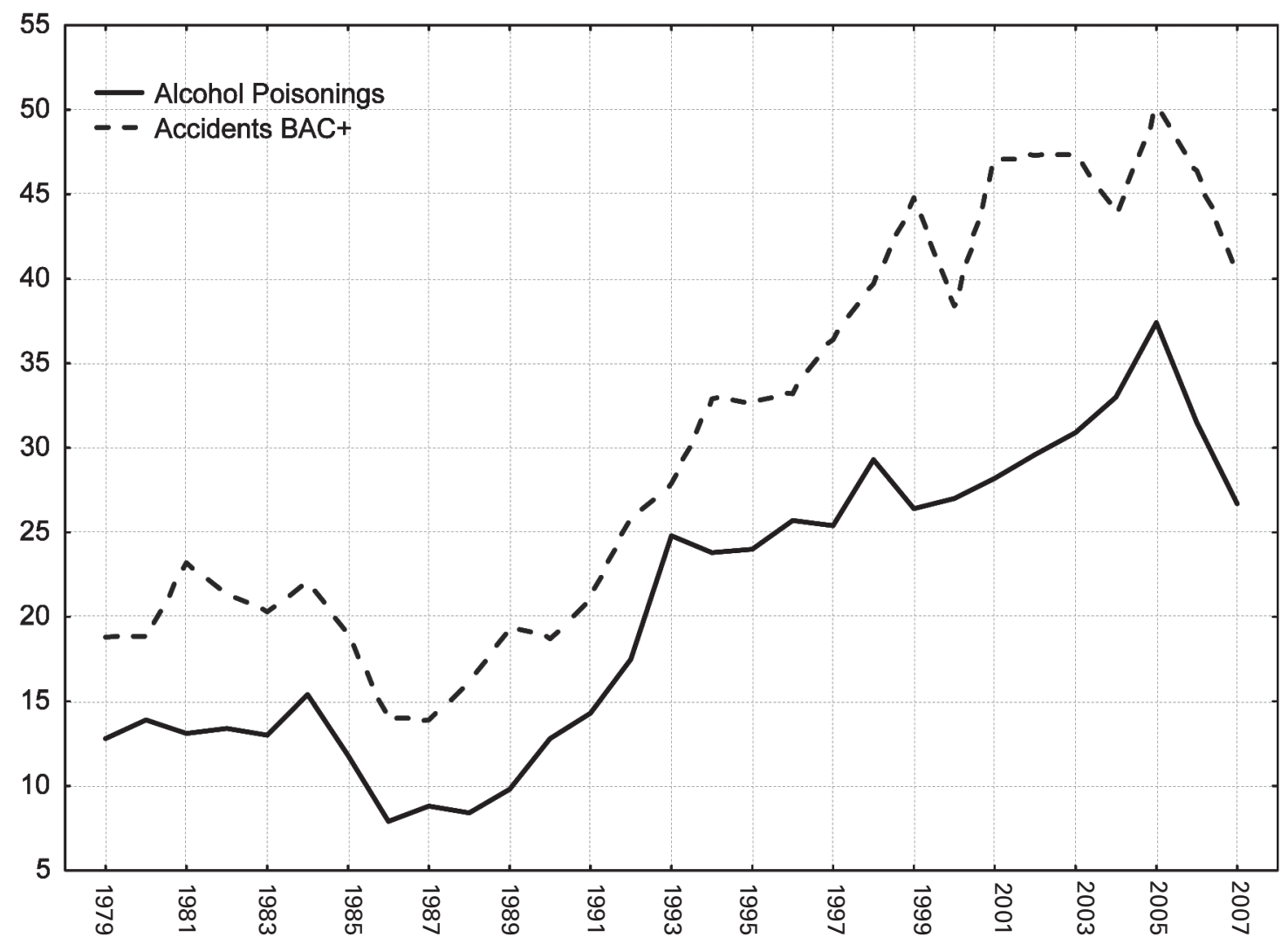

Figure 2. Trends in the number of BAC-positive cases of deaths from accidents and injuries and the number of fatal alcohol poisoning cases in Belarus between 1979 and 2007. 
Table 1. The results of cross-correlation analysis between prewhitened time series of alcohol poisonings and accident mortality rates.

\begin{tabular}{|c|c|c|c|c|}
\hline & \multicolumn{2}{|c|}{$\begin{array}{c}\text { Alcohol poisonings } \\
\text { BAC+ Accidents }\end{array}$} & \multicolumn{2}{c|}{$\begin{array}{c}\text { Alcohol poisonings } \\
\text { BAC- Accidents }\end{array}$} \\
\hline Lag & $r$ & SE & $r$ & SE \\
\hline-3 & -0.011 & 0.200 & 0.044 & 0.200 \\
\hline-2 & -0.211 & 0.196 & -0.171 & 0.196 \\
\hline-1 & 0.212 & 0.193 & 0.293 & 0.193 \\
\hline 0 & 0.465 & 0.189 & -0.013 & 0.189 \\
\hline 1 & 0.215 & 0.193 & 0.032 & 0.193 \\
\hline 2 & -0.014 & 0.196 & 0.246 & 0.196 \\
\hline 3 & 0.132 & 0.200 & 0.113 & 0.200 \\
\hline
\end{tabular}

Table 2. The results of distributed lags analysis between prewhitened time series of alcohol poisonings and accident mortality rates.

\begin{tabular}{|c|c|c|c|c|}
\hline Lag & Regres Coeff & Standard Error & $\mathrm{t}$ & $\mathrm{p}$ \\
\hline 0 & 0.521 & 0.212 & 2.144 & 0.003 \\
\hline 1 & 0.433 & 0.240 & 1.57 & 0.325 \\
\hline 2 & -0.324 & 0.321 & -0.039 & 0.556 \\
\hline 3 & -0.084 & 0.382 & -0.256 & 0.751 \\
\hline
\end{tabular}

The dramatic development in accident mortality rate in Belarus coincided with two major political events: the antialcohol campaign during the mid-1980s, and the political and economic transition following the break up of the Soviet Union in 1991. A fairly close match between trends in fatal alcohol poisoning and accidental deaths during anti-alcohol campaign may be use as evidence for the hypothesis suggesting that alcohol was the main contributing factor of fluctuation in accident mortality rate in Belarus during the last decades.

The results from the time series analysis suggest positive relationship between fatal alcohol poisonings (as a proxy for binge drinking) and accidental deaths at zero lag. In this case the independent variable is directly influencing the dependent variable and there is no evidence of a lagged relationship between the two time series. This may support the point that binge drinking, which results in a quicker and deeper intoxication is a risk factor for fatal accidents.

This evidence is consistent with the findings from previous studies indicating that binge drinking is associated with high risk of trauma (Bondy, 1996; McLeon, Stockwell, Stevens \& Phillips, 1999; Watt, Purdie, Roche \& McClure, 2004). Savola and coauthors (2005) reported that binge drinking is a major risk factor for head trauma among trauma patients and that the relative risk for head injury markedly increases with increasing blood alcohol level. In recent study from Finland was shown an excess of head traumas during weekends and this excess was associated with heave episodic drinking (Puljula, Savola, Tuomivaara, Pribula \& Hillbom, 2007). Similar weekly variations of head trauma have been reported in other countries where heavy episodic drinking is also the prevailing drinking pattern (Chenet, Britton, Kalediene \& Petrauskiene, 2001).

There is also research evidence that in the FSR accident mortality rate is more responsive to per capita changes in distilled spirits consumption rather than in the total level of alcohol consumption. In particular, the results from recent time series analysis based on Russian data from 1980 to 2005 suggest that 1 litre increase in overall alcohol sale would result in a $4.6 \%$ increase in the accident mortality rate, while a 1 litre increase in vodka sales is expected to increase the number of deaths from accidents and injuries by $11 \%$ (Razvodovsky, 2010). Similar results have been reported in the time-series analysis based on Belarussian data from the period 1970-2005 (Razvodovsky 2008). It was estimated that 1 litre increase in alcohol sale is associated with a $6.2 \%$ increase in the number of deaths from accidents and injuries; a 1 litre increase in vodka sales would result in a $10.7 \%$ increase the accidental mortality rate. Collectively, these findings provided support for the hypothesis that binge drinking of vodka is a major determinant of accident mortality crisis in the FSR.

Before concluding, it is necessary to consider the potential limitations of this study. This principally applies to the quality of the data used. An earlier study of violent mortality data from the Soviet period concluded that they were not deliberately falsified in Belarus (Wasserman \& Varnik, 1998) while a recent study has argued that comparisons can be made across time in the country using Soviet and post-Soviet data (Stickley et al. 2007). Finally, it should be kept in mind that the current analysis is based on relatively few observations in the time series.

In conclusion, this study suggests a close link between alcohol and mortality due to accidents and injuries at the individual and aggregate levels in the country with prevailing intoxication-oriented drinking pattern. This research evidence points to binge drinking pattern as a potentially important contributor to accident mortality crisis in Belarus. The results of present study, as well as findings from other settings indicate that a restrictive alcohol policy can be considered as an effective measure of accidental deaths prevention in countries where rates of both alcohol consumption and accident mortality are high.

\section{REFERENCES}

1. Anda, R.F., Williamson, D.F., Remington P.L. (1995). Alcohol and fatal injuries among US adults. Journal of the American Medical Association, 260,2529-2532.

2. Anderson, P. \& Baumberg, B. (2006). Alcohol in Europe. A public health perspective. A report for the European Commission, Institute of Alcohol Studies, UK.

3. Bondy, S.J. (1996). Overview of studies on drinking patterns and consequences. Addiction, 91(11), 1663-1674. 
4. Box, G.E.P., Jenkins, G.M. (1976). Time Series Analysis: forecasting and control. London. Holden-Day Inc.

5. Chenet, L., Britton, A., Kalediene, R., Petrauskiene, J. (2001). Daily variations in deaths in Lithuania: the possible contribution of binge drinking. International Journal of Epidemiology, 30,743748.

6. Cherpitel, C.J. (1993) Alcohol and injuries: A review of international emergency room studies. Addiction,88,923-937.

7. Cherpitel, C.J., Moskalewicz, J., Swiatkiewicz, G. (2004). Drinking patterns and problems in emergency services in Poland. Alcohol \& Alcoholism, 39(3), 256-261.

8. Cunningham, R.M., Maio, R.F., Hill, E.M., Zink, B.J. (2002). The effects of alcohol on head injury in the motor vehicle crash victim. Alcohol \& Alcoholism, 37(3), 236-240.

9. Edwards, G., Anderson, P., Babor, T.F., Casswell, S., Ferrence, R., Giesbrecht, N., Godfrey, C., Holder, H.P., Lemmens, P.H.M.M. (1994). Alcohol policy and the public good. Oxford: Oxford University Press.

10. Higson, R., Howland J. (1987). Alcohol as a risk factor for injury of death resulting from accidental falls: a review of the literature. Journal of Studies on Alcohol, 48, 212-219.

11. Landberg J. (2010). Population drinking and fatal injuries in Eastern Europe: a time-series analysis of six countries. Eur Addict Res, 16, 43-52.

12. Makela, P. (1998). Alcohol-related mortality by age and sex and its impact on life expectancy. Estimates based on the Finnish death register. European Journal of Public Health, 8, 43-51.

13. Mayhew, D.R., Donelson, A.C., Beirness, D.J., Simpson, H.M. (1986). Youth, alcohol and relative risk of crash involvement. Accident Analysis and Prevention, 18, 273-287.

14. McLeon, R., Stockwell, T., Stevens, M., Phillips, M. (1999). The relationship between alcohol consumption patterns and injury. Addiction, 94,1719-1734.

15. Moskalewicz, J., Razvodovsky, Y., Wieczorek, P. (2009). East-West disparities in alcohol-related harm within European Union. Paper presented at the KBS Annual Conference, Copenhagen, 1-5 June, 2009.

16. Mravik, V., Vorel, F., Zabransky, T. (2007). Drugs and fatal traffic accidents in the Czech republics. Cent Eur J Public Health, 15, 158-162.

17. Nemtsov, A.V., Razvodovsky, Y.E. (2008). Alcohol situation in Russia, 1980-2005. Social and Clinical Psychiatry, 2, 52-60.

18. Noland, R.B. (2003). Traffic fatalities and injuries: the effect of changes in infrastructure and other trends. Accid Anal Prev, 35,599-611.

19. Norstrom, T, Ramstedt, M. (2005). Mortality and population drinking: a review of the literature. Drug and Alcohol Review, 24,537-547.

20. Pérez, K., Santamariña-Rubio, E., Rodríguez-Martos, A., Brugal, M.T., Ricart, I., Suelves, J.M., de la Torre, R., Pujadas, M., Ariza, C., Díez, E., Nepot, M., Ramos, P., Martinez Beneyto, V., Plasència, A. (2009). Substance use among non-fatally injured patients attended at emergency departments in Spain. Drug Alcohol Dependence, 105(3),194-201.
21. Pridemore, W.A. (2006). Heavy drinking and suicide in Russia. Social Forces, 85(1), 413-430.

22. Puljula, J., Savola, O., Tuomivaara, V., Pribula, J., Hillbom, M. (2007). Weekday distribution of head traumas in patients admitted to the emergency department of a city hospital: effects of age, gender and drinking pattern. Alcohol \& Alcoholism, 42, 474-479.

23. Razvodovsky, Y.E. (2001). The association between the level of vodka consumption per capita and violent mortality rate: results of time-series analysis. Adicciones, 13(Suppl.1), 77-92.

24. Razvodovsky, Y.E. (2008). Indicators of alcohol-related problems in Belarus. Grodno. Medical University Press.

25. Razvodovsky, Y.E. (2010). Beverage-specific alcohol sales and violent mortality in Russia. Adicciones, 22, 311-316.

26. Rehm J, Sulkowska U, Manczuk M, Boffeta P, Powles J, Popova S, Zatonski W. (2007). Alcohol accounts for a high proportion of premature mortality in central and Eastern Europe. International Journal of Epidemiology, 36, 458-67.

27. Rivara, F.P., Jurkovich, G.J., Gurney, J.G., Seguin, D., Fligner, C.L., Ries, R., Raisys, V.A., Copass, M. (1993). The magnitude of acute and chronic alcohol abuse in trauma patients. Arch Surg, 28, 907-913.

28. Savola, O., Niemela, O., Hillbom, M. (2005). Alcohol intake and the pattern of trauma in young adults and working aged people admitted after trauma. Alcohol \& Alcoholism, 40, 269-273.

29. Savola, 0., Niemela, O., Hillbom, M. (2005). Alcohol intake and the pattern of trauma in young adults and working aged people admitted after trauma. Alcohol \& Alcoholism, 40, 269-273.

30. Skog, 0.J. (1986). Trends in alcohol consumption and violent deaths. British Journal of Addiction, 81, 365-379.

31. Skog, 0.J. (2001a). Alcohol consumption and mortality rates from traffic accidents, accidental falls, and other accidents in 14 European countries. Addiction, 96,49-58.

32. Skog, 0.J. (2001b). Alcohol consumption and overall accidental mortality in 14 European countries. Addiction, 96, 35-47.

33. Skog, O.J. (2003) Alcohol and fatal accidents in Canada 19501998. Addiction, 98,883-893.

34. Stickley, A., Leinsalu, M., Andreew, E., Razvodovsky, Y.E., Vagero, D., McKee, M. (2007). Alcohol poisoning in Russia and the countries in the European part of the former Soviet Union, 1970-2002. European Journal of Public Health, 17(5), 444-449.

35. Treno, A., Gruenewald, P.J., Ponicki, W.R. (1997). The contribution of drinking patterns to the relative risk of injury in six communities: a self report bases probability approach. Journal of Studies on Alcohol, 58, 372-381.

36. Wasserman, D., Varnik, A. (1998). Reliability of statistics on violent deaths and suicide in the former USSR, 1970-1990. Acta Psychiatrica Scandinavica, 394 (Suppl.), 34-41.

37. Watt, K., Purdie, D.M., Roche, A.M., McClure, R.J. (2004). Risk of injury from acute alcohol consumption and the influence of confounders. Addiction, 99, 1262-1273.

38. Zador, P.L. (1991). Alcohol-related relative risk of fatal driver injuries in relation to driver age and sex. Journal of Studies on Alcohol, 52, 302-310. 